\title{
Comment
}

\section{O Que Vou Ser Quando Crescer: A Relação Entre a Atividade Profissional e a Perspectiva de Atuação após o fim do Curso de Graduação}

Fernanda Roda de Souza Araújo Cassundé ; Antônio Jessé Alves de Lima $^{2}$; Camila Vieira Rodrigues ${ }^{3}$; Cláudio Alberto de Sá Quirino ${ }^{4}$; Leonardo Guerra Maia ${ }^{5}$

\begin{abstract}
Resumo: Globalização, tecnologias de informação, valorização do capital intelectual e exigências do mercado têm provocado significativas mudanças no mundo do trabalho. Assim, é objetivo do artigo traçar o perfil que evidencie a relação entre atividades profissionais dos estudantes dos dois últimos anos de Administração da UNIVASF e a sua perspectiva de atuação após o curso. Para isso, foram utilizados 60 questionários aplicados aleatoriamente. Conclui-se que há a predisposição dos estudantes, pelas áreas de maior relevância no mercado de trabalho local, especialmente no setor privado e que o curso de Administração é um dos que, por seu amplo campo de atuação e particularidade curricular, tem motivado estudantes quanto à decisão sobre o rumo das suas carreiras após a graduação e constituído habilidades que nortearão escolhas, porém nem sempre o fato está associado ao papel que exercem no ambiente de trabalho, implicando em insatisfações, estresse e desempenhos ruins.
\end{abstract}

Palavras-chave: Atividade profissional; gestão de carreiras; estudantes do curso de Administração; mercado de trabalho.

\section{What I Will be When I Grow up? The Relationship Between the Professional Activity and the Performance of Perspective After the End of Graduation}

\begin{abstract}
Globalization, information technology, enhancement of intellectual capital and market requirements have led to significant changes in the working world. It is therefore aim of the paper outlining the profile that shows the relationship between professional activities of the students of the last two years of Directors of UNIVASF and your perspective of action after the course. For this, we used 60 questionnaires randomly. We conclude that there is the willingness of students in areas of high relevance in the local labor market, especially in the private sector and that the course of Directors is one that, by its wide field of action and curriculum particularity, has motivated students and the decision on the direction of their careers after graduation and consists skills that will guide choices, but not always the fact is associated with the role they play in the workplace, resulting in dissatisfaction, stress and bad performances.
\end{abstract}

Keywords: Professional activity; career management; business course students; labor market

\section{Introdução}

As grandes mudanças sofridas pelo mercado de trabalho têm construído uma nova realidade não somente para as organizações, que, para continuar sobrevivendo diante de um cenário competitivo, precisa a cada momento implementar novas ações estratégicas e tornar mais dinâmicas relações com o mundo, mas também para a grande parcela da população que aspira à vida profissional sólida.

\footnotetext{
${ }^{1}$ Graduação em Administração pela Universidade Federal de Pernambuco (2001) e Mestrado em Administração pela Universidade Federal de Pernambuco (2004). Doutoranda em Administração no programa DINTER - UNIVASF/PROPAD. Atualmente é professora Assistente II do colegiado de Administração da Universidade Federal do Vale do São Francisco (UNIVASF) e Pesquisadora de projeto apoiado pelo CNPq cujo tema refere-se ao desenvolvimento de competências docentes para EAD. Email: fernanda.roda@univasf.edu.br

${ }^{2}$ Acadêmico de Administração da UNIVASF. E-Mail: a.jesse078@gmail.com;

${ }^{3}$ Acadêmico de Administração da UNIVASF. E-Mail:milajua_2006@ hotmail.com;

${ }^{4}$ Acadêmico de Administração da UNIVASF. E-Mail: claudioquirino86@bol.com.br;

${ }^{5}$ Acadêmico de Administração da UNIVASF. E-Mail: leoguerramaia@ hotmail.com.
} 
São as estatísticas que apontam que, a cada dia, postos de trabalho estão sendo consideravelmente reduzidos. No Brasil, segundo as pesquisas do DIEESE (2010), 42\% dos jovens encontram-se em situação de desemprego e a busca por cargos e pelos empregos estáveis tem sido observada ao longo dos estudos. Essa realidade tem obrigado jovens a tentarem importantes medidas para se diferenciar dos concorrentes e, pela conformação do mercado de trabalho, tudo indica que investir em educação continuada ainda é a melhor solução para se conquistar um emprego que atenda aos requisitos pessoais e expectativas do indivíduo.

É uma das características do mercado de trabalho concentrar esforços naqueles que, por contribuições e especialização curricular, demonstram a melhor concepção do ambiente de trabalho em que atua e apresenta domínio conceitual maior em relação aos concorrentes. Entre os indicadores que evidenciam o nível de aptidão, o conhecimento e as habilidades do profissional, certamente especialização é uma produtiva conquista para se firmar na função e um instrumento sem o qual não é possível, no contexto moderno, valorizar e desenvolver as potencialidades (MALSCHITZKY, 2004).

As tecnologias, processo de comunicação, os trabalhos flexíveis e novas formas das hierarquias organizacionais têm aberto os caminhos e oportunidades para profissionais que estão dispostos a enfrentar grandes desafios e de superá-los, a fim de conquistar seu espaço. Nem sempre é possível afirmar que todos aqueles que estão engajados na vida profissional está satisfeito com o posto que ocupa, e isso pode ser reflexo de diversas causas associadas, na maioria das vezes, às expectativas e nível de necessidade básica. Melo (2010) discute o papel dos cursos de graduação e coloca que são universidades e faculdades que promovem a consciência crítica e uma nova postura em relação à formação dos futuros profissionais, visando prepará-los para o mercado e as suas adversidades.

Certamente, são universidades e faculdades que estimulam o conhecimento e prepara o indivíduo para o futuro. Ao longo da rotina acadêmica, o estudante é mergulhado em uma proposta curricular que apresenta as ferramentas para a sua formação e especialização e, em função disso, habilidades são trabalhadas durante o período do curso. Segundo Bendassolli (2009), estudantes passam por processo de transformação, adquirindo grau de experiência e se tornando aptos a construírem critérios que definirão a sua escolha quanto à carreira e sua vida profissional. É durante a graduação, especialmente nos últimos anos do curso, que o estudante tem condições de, a partir das influências do meio e das suas preferências, avaliar as alternativas, construir o planejamento da carreira e a sua orientação profissional.

Ao mesmo tempo em que freqüentam os cursos de graduação, os estudantes também precisam dedicar parte do seu tempo ao trabalho, atividade fundamental ao próprio sustento e satisfação das necessidades e de sua família. Segundo Veloso (2011), a rotina acadêmica e atividades profissionais desempenhadas pelo estudante fazem parte do desenvolvimento pessoal, do atual contexto e promove as transformações no processo de decisão da carreira profissional e na visão das exigências solicitadas pelo mercado. O desafio é, sem dúvida, conciliar a atual atividade profissional com as expectativas

191 Id en lime Revista de Psicologia. Ano 9, No. 26, Supl. Esp. Abril/2015 - ISSN 1981-1179. Edição eletrônica em http://idonline.emnuvens.com.br/id 
após o curso. Nesse sentido, este artigo busca desenvolver o panorama do curso de Administração da UNIVASF e, com base em informações e dados disponíveis, definir o perfil dos estudantes dos quatro últimos períodos, relacionando a orientação profissional e expectativa de carreira futura com a sua atividade atual.

\section{O Mercado de Trabalho no Brasil}

O mercado de trabalho brasileiro tem apresentado sérias distorções em seus principais índices de empregabilidade, principalmente no que tange às oportunidades aos jovens, que, cada vez mais, encontram dificuldades para ingressar no primeiro emprego e essa situação está consideravelmente provocando transformações na conjuntura do mercado de trabalho brasileiro. A empregabilidade dos jovens é um desafio a ser solucionado e necessidade das políticas de acesso e estratégias de trabalho têm sido discutidas, embora ainda não estejam completamente atuantes.

Segundo Gomes (2009), somente no Brasil, cerca de 80 milhões de jovens buscarão as oportunidades de emprego nos próximos dez anos (2010-2020). Estudos na área e novas pesquisas indicam que são muitos os fatores que, de alguma maneira, contribuem para esse crescimento, uma vez que postos de trabalho não são suficientes para comportar a procura, entre eles estão a crise mundial e o desemprego generalizado. Dados do IBGE (2012), entre 2004 a 2011, indicam que número de trabalhadores com carteira assinada no setor privado cresceu $48 \%$ e a participação do emprego formal passou de 39,7\%, em 2003, para 48,5\% no ano de 2011.

Os sem carteira foram de $15,5 \%$ para $11,1 \%$ e os trabalhadores por conta própria, de $20 \%$ para 17,9\%. Em dezembro de 2011, o número de empregados com registro foi de 11,2 milhões, para 22,7 milhões. O crescimento do emprego formal em 2011 foi bem semelhante ao do ano anterior $(6,8 \%$ ante 7,2\%). Já acrescimento da ocupação foi de 2,1\% (2011), ante 3,5\% entre 2009 e 2010. A ocupação apresentou um crescimento na ordem de 21,3\%. Em igual período, o total de desempregados caiu $45,3 \%$ (IBGE, 2012).

A escolaridade também apresentou crescimento, e isso tem evidenciado que educação e a busca por especialização e a capacitação tem sido a saída para muitas pessoas, inclusive jovens brasileiros que, cada vez mais, está percebendo ser essa a melhor alternativa para o acesso ao mercado de trabalho (IBGE, 2012).

\section{As Dificuldades de Acesso Profissional}

Apesar do crescimento nos fatores que evidenciam a situação da empregabilidade no Brasil, 
ainda é possível encontrar distorções quanto ao acesso ao mercado de trabalho, entre elas a mão-deobra excessiva dos trabalhadores mais experientes e qualificados, que tende a reduzir as oportunidades dos que acabaram de finalizar a graduação e pretendem ingressar na carreira.

O segundo fator relaciona-se com formação educacional de jovens que, devido a falta da consolidação da matriz curricular, ainda fica a desejar em diversos centros universitários e, por último, falta de experiência desse público em relação ao funcionamento do mercado e suas adversidades, capacitando-os para enfrentar grandes desafios de forma empreendedora e competitiva. Dos indicadores supracitados, o aumento do desemprego entre os instruídos, ou seja, os detentores de diploma de graduação, é o que carece de melhores investimentos e de muitas ações preventivas, no sentido de minimizar os impactos na evolução do mercado de trabalho brasileiro (Lacombe, 2002).

Conforme estudo de Melo (2010), as condições de acesso aos postos de trabalho para os jovens com curso superior concluído têm apresentado consideráveis crescimentos, uma vez que estes estão em busca do conhecimento continuado e de capacitações cada vez mais direcionadas a satisfação das exigências do mercado (um autogerenciamento da carreira, a especialização, trabalho com significado, desenvolvimento de liderança, entre outros).

\section{O Papel da Universidade na Orientação Profissional}

Dos ambientes que priorizam a formação continuada e a preparação para um futuro profissional, a universidade é, sem dúvida alguma, o principal meio para instrumentalizar o acesso à informação sobre o mercado de trabalho, as tendências profissionais, orientar o planejamento da carreira e de apresentar, a partir do currículo, os caminhos necessários a consolidação de uma vida estável. De fato, universidades e faculdades têm desempenhado o papel fundamental no gerenciamento profissional e construído caminhos para oportunizar o ingresso do estudante nos postos de trabalho. De acordo com Voese (2007), a instituição de ensino superior permite que o indivíduo busque qualificação e preparo para o mercado de trabalho. Com a formação acadêmica, poderá agregar novas informações e conhecimentos a seu perfil.

O desenvolvimento das competências, aptidões e habilidades profissionais estão cada vez presentes na composição da matriz curricular de cursos de graduação do país, buscando dar ao estudante um direcionamento mais acertado sobre o comportamento do mercado de trabalho e as características exigidas para o novo perfil profissional. Um dos aspectos da realidade é que os indivíduos mais preparados conquistam os melhores cargos e empregos, independente do setor em que diretamente atue, graças ao planejamento pessoal da carreira e de suas expectativas de trabalho.

Milioni (2004), aborda o planejamento de carreira como a metodologia que orienta a arquitetura de desenvolvimento do indivíduo levando em conta os talentos, os potenciais e as 
experiências em precisa sintonia com as perspectivas da organização.

Segunda Dutra (1998), são orientações básicas do planejamento de carreira:

a) Coletar informações sobre si mesmo e sobre o mundo do trabalho;

b) Traçar um perfil detalhado de suas características de personalidade, interesses e aptidões, possibilidades de atuação no mercado de trabalho e ocupações alternativas;

c) Estabelecer metas realistas, baseadas nessas informações e implementar estratégias para o alcance dessas metas.

O ideal seria iniciar planejamento de carreira dentro do ambiente universitário, ainda na fase acadêmica. Assim, o aluno poderia também trabalhar suas expectativas e começar a vida profissional, através de estágios, já com prévio acompanhamento e planejamento, além de desenvolver as habilidades relacionais em uma fase da vida tão propícia, aumentando e fortalecendo sua rede social. $\mathrm{O}$ aluno ainda poderia participar dos cursos extracurriculares, que o auxiliaria a trabalhar competências, ajudando-o a enfrentar de forma eficaz o acirrado mercado de trabalho (BALASSIANO, 2006).

É importante que o estudante não tenha visão idealizada acerca do que encontrará ao se formar; daí a relevância da pesquisa sobre fatores limitantes e facilitadores da inserção no mercado de trabalho (COSTA, 2007).

\section{Expectativas de Carreira para a Administração}

A Administração é o resultado da necessidade de gerenciar organizações e de nortear, através da implementação dos programas e de ações estratégicas, uma visão mais aberta e consciente do mundo. Apresentando um leque bastante amplo de atuação do profissional - Marketing, Produção, Finanças, a Logística, Comercial, a Gestão de Pessoas, Tecnologia da Informação, entre outros -, a Administração está cada vez mais atraindo os estudantes em função da diversidade curricular e de um mercado de trabalho estimulante.

A busca pela estabilidade no setor público ou privado, a preferência pela atividade empreendedora, magistério acadêmico, além de outras motivações, estimulam estudos para entender comportamento e perfil de estudantes de Administração em relação a expectativas de carreira e mercado de trabalho oferecido para esses profissionais. Os dados da pesquisa realizada pelo Conselho Federal da Administração (CFA), no ano de 2011, indicam como estudantes dos cursos de Administração enxergam o mercado de trabalho, as oportunidades e realiza um levantamento para conhecer a verdadeira motivação quanto à continuidade.

Entre as principais motivações apresentadas estão a preferência pelas ciências sociais $(5,13 \%)$, amplo mercado de trabalho $(21,29 \%)$, a vocação $(18,35 \%)$, atuação na empresa familiar $(3,89 \%)$, abrir 
negócio $(5,75 \%)$ e alternativas de especialização $(8,17 \%)$ (CFA, 2011). A pesquisa descreve indicadores quanto ao local de sua atuação e, em relação a esse aspecto, temos que a Administração Geral concentra $42,26 \%$, seguida da área financeira $(4,97 \%)$, as Vendas $(4,14 \%)$ e RH $(2,64 \%)$. As informações indicam a concentração de profissionais e a distribuição através dos segmentos, ampliando participação na composição do trabalho e oportunidades que podem ser seguidas pelos estudantes para o planejamento e orientação profissional (CFA, 2011).

Quanto às áreas promissoras para contratação dos administradores, segundo dados do CFA (2011), os segmentos que mais atraem os estudantes do curso de Administração são a consultoria empresarial (49,14\%), os serviços $(46,13 \%)$, a administração indireta $(38,17 \%)$, a industrial $(31,27 \%)$, as empresas financeiras $(34,21 \%)$ e hotelaria $(38,51 \%)$. No Nordeste, a área de consultoria prepondera $(50,2 \%)$, seguida pelos serviços $(46,6 \%)$ e a administração indireta $(38,9 \%)$, hotelaria $(37,6 \%)$ e a administração pública direta $(37,4 \%)$ também foram indicadas como promissoras, indicando que existe o mercado bastante amplo para absorver esses profissionais.

\section{O Novo Perfil do Administrador}

O administrador é considerado o recurso importante de uma organização, que provê os instrumentos necessários para o gerenciamento do processo e dos recursos empresariais. Para acompanhar essa evolução da visão administrativa, é preciso buscar aperfeiçoamento e novos conhecimentos, acompanhando desenvolvimento da organização e da sociedade que a estimula. Devem manter-se atentos e ativos, procurando sempre adquirir competências e habilidades que precisarão no futuro (DRUCKER, 2002).

Para Drucker (2002), a primeira função de um administrador é fornecer os resultados econômicos para uma empresa. Se o mesmo não aumentar ou mantiver a fonte geradora de recursos econômicos, a administração deixa de ser considerada uma função tão especial. O administrador deve, certamente, compreender o que a organização tem como objetivos e a partir daí, planejar ações estratégicas através da organização, direção e controle de todas as pessoas e todas as áreas envolvidas para atingir tais objetivos.

Com base nas evidências da literatura, percebe-se que a carreira administrativa pode ser muito promissora. Os cargos e as funções que compõem as atividades de gerenciamento público ou privado, dão aos administradores status e prestígio. Geralmente, possuem bons salários e benefícios, além de oferecer satisfação social e contato com diversas pessoas. Segundo as considerações de Melo (2007), as atividades de um administrador precisam ser conduzidas, planejadas e realizadas em áreas específicas dentro das organizações. Dessa forma, faz-se necessário que o administrador tenha 
formação profissional que ultrapasse as salas de aula, garantindo-lhe visão ampla e sistêmica de suas funções.

Levando em consideração o contexto atual, o novo perfil dos administradores é de um envolvimento cada vez maior em trabalhos em equipes, rígidos limites éticos, de constante atualização e melhor aperfeiçoamento, planejamento estratégico, de responsabilidade social e ambiental (WEIBLEN, 2004). Assim, o administrador estará conquistando cada vez mais um diferencial que caracterize a sua modalidade de trabalho, respeitando as condições do mercado e as exigências, habilidades e aptidões requeridas desse profissional.

$\mathrm{O}$ administrador deve ser um agente que promova e estimule significativas mudanças em seu ambiente de trabalho e sua rotina profissional, deve exercer um papel de educador e orientador capaz de modificar comportamentos das pessoas, atitudes e inclusive, influenciar a cultura e clima dentro das organizações. Para isso, o profissional da administração precisa de criatividade, agilidade, capacidade de adaptar-se continuamente, confiança e constância em seus sistemas de gestão (MELO, 2007).

\section{Método}

O presente artigo tem intuito de discutir, na forma de estudo de caso com revisão bibliográfica, um perfil dos estudantes dos dois últimos anos do curso de Administração da Universidade Federal do Vale do São Francisco (UNIVASF) em relação às expectativas de carreira futura e atual atividade profissional.

Apresenta-se uma metodologia predominantemente descritiva e explicativa, uma vez que se está propondo realizar descrições precisas da situação e descobrir as relações existentes entre os elementos componentes da mesma (CRESWELL, 2010)

Para atingimento do objetivo proposto foi utilizado como instrumento de coleta de dados um questionário dividido em duas grandes seções: uma sobre o perfil profissional do respondente e outra sobre a perspectiva de atuação após a conclusão do curso de graduação em Administração. De maneira aleatória 60 (sessenta) questionários padronizados do $6^{\circ}$ ao $9^{\circ}$ período foram aplicados em novembro de 2014. A amostra foi calculada a partir do número total de alunos matriculados do $6^{\circ}$ ao $9^{\circ}$ período e considerando-se um considerando-se 68\% de representatividade (RICHARDSON, 2007). A amostra escolhida para a composição a base de dados para análise apresenta caráter intencional por acessibilidade.

Os dados colhidos dos questionários serviram para a elaboração de tabelas e gráficos comparativos, a partir dos quais foram montadas estruturas de análise e evidências que fossem capazes de definir o panorama de estudantes de Administração e satisfatoriamente respondesse aos objetivos da pesquisa. 


\section{Análise dos Dados}

\section{Perfil Profissional}

Foram aplicados, nos períodos considerados para compor a pesquisa de perfil, o total de 60 (sessenta) questionários, e, dentro do total dos respondentes, ficou observado que os discentes dos quatro últimos anos de Administração da UNIVASF e, desse contingente, $61 \%$ são homens e $39 \%$ mulheres.

Quanto à composição da faixa etária, percebeu-se que 52\% dos respondentes têm entre 21 a 25 anos, demonstrando maior participação e interesse maior dos jovens quanto à graduação em Administração; $20 \%$ dos sujeitos estão entre 26 a 30 anos e, mais uma vez, o valor confirma que discentes da graduação são bem mais jovens que os demais segmentos considerados no questionário, ficando estes com um total de $22 \%$ (sujeitos com mais de 30 anos e frequentam regularmente).

Um indicador que tem motivado jovens a optarem pelo curso de Administração é a atratividade do mercado de trabalho oferecido ao profissional, além do amplo campo de atuação, expansão dos postos de trabalho em função do aumento da abertura das empresas carentes de melhor gerenciamento e melhores possibilidades de especialização (VELOSO, 2011). Entre fatores que estão contribuindo consideravelmente para a chegada das pessoas acima de 30 anos à universidade encontram-se a necessidade de novos conhecimentos para administração de um negócio, a perspectiva de mudar de área e demais fatores supracitados (PORTUGAL, 2012).

Sobre o quantitativo de respondentes que, ao mesmo tempo em que estudam, também trabalham para prover o sustento próprio e da família, observou-se que predominantemente $80 \%$ dos graduandos encontram-se trabalhando. Esse é, sem dúvidas, um dos indicadores fundamentais para traçar o perfil atuação profissional/expectativas de atuação após o curso, pois, a partir dele, é possível construir uma visão mais minuciosa acerca dos estudantes de Administração, revelando evidências sobre níveis profissionais e sua satisfação no trabalho. Para fundamentar a relevância de estar trabalhando enquanto frequenta um curso superior, Cardoso (2004), estudou uma amostra dos jovens universitários no Brasil e encontrou que trabalhar significa, em muitos casos, obter a renda desempenhando uma tarefa qualquer.

O resultado representa a autonomia, tanto em relação à não dependência da família, quanto à entrada em estilo de vida jovem com condições de moradia, consumo e lazer. No curso de Administração, encontrou $72 \%$ de estudantes trabalhando. Também encontrou que os estudantes acabam se engajando no mercado através das funções não necessariamente vinculadas ao campo de estudo. Entre aqueles que trabalham e tempo na função atual, $40 \%$ está no mesmo local de trabalho entre 1 a 3 anos, indicando um tempo de vínculo que tende a ser duradouro, podendo indicar fidelidade à empresa e alguns estímulos como benefícios e oportunidades de crescimento e 
desenvolvimento profissional (COSTA, 2007).

No entanto, apesar de maior tempo de vínculo, há contraste em relação aos salários. Pelos indicativos, 41 \% recebem remuneração entre $\mathrm{R} \$ 726,01$ e $\mathrm{R} \$ 1.500,00$, com valores variando, nesse sentido; a outra parcela, com 20\%, ganha menos de um salário mínimo (R \$ 726,00) e, conforme resultado, esses valores são traduzidos em insatisfações no trabalho, na expressiva vontade de mudar de cargos e novas aspirações profissionais. $61 \%$ afirmam que não pretende seguir no mesmo emprego, depois da graduação.

Existe uma perspectiva dos cursistas em relação à atividade profissional exercida e às perspectivas do mercado para o administrador. Sarsur, Cruz e Barbosa (2002) pesquisaram amostra de 141 graduandos em Administração e que se encontravam na segunda metade do curso, sendo alguns inseridos no mercado. Os autores concluíram que, apesar de estarem atentos a demandas do mercado, ao serem questionados sobre chances depois da graduação, 51,06\% deles apontaram para obtenção de emprego fixo. Somente $19,86 \%$ acreditavam que trabalhariam como empreendedores e 83,69\% consideravam pouco provável a possibilidade de ficarem desempregados.

Sobre o vínculo profissional dos pesquisados, os dados da pesquisa apontam que $48 \%$ estão vinculados ao setor privado e $27 \%$ ao setor público, e estes são os dois segmentos que mais estimulam os profissionais, absorvendo a maior parte dos administradores disponíveis por conta dos atrativos oferecidos. Segundo pesquisa realizada pelo CFA (2011), o índice dos que declaram possuir a carteira profissional assinada aumentou comparativamente às pesquisas anteriores (67,87\% em 2006 e 78,48\% em 2011). O setor empreendedor, com 15\%, também está entre segmentos de maior representatividade, graças a incentivos fiscais, a participação das empresas responsáveis pela capacitação dos profissionais, a exemplo do SEBRAE, além da realização pessoal e lucro (BORGES, 2013).

\section{A Perspectiva de atuação após a Graduação}

Sobre as perspectivas dos graduandos dos últimos dois anos de Administração e a sua atuação profissional após o curso, é importante descrever alguns critérios e indicadores que dimensionam o seu grau de conhecimento em relação ao mercado de trabalho. Para iniciar a modelagem do perfil, é preciso conhecer as preferências acerca das áreas da Administração. Conforme os dados, Administração Geral conquistou 28\%, seguida pela Gestão de Pessoas (22\%), Finanças (16\%), Marketing (14\%) e o resultado apresentado, especialmente quanto à Administração Geral, surpreendeu muito em detrimento das demais áreas, tendo em vista que, geralmente, a área de Marketing e Gestão de Pessoas são as mais escolhidas, segundo resultados da pesquisa de Cardoso (2004), cujas áreas atraíram, respectivamente, $28 \%$ e 19\%, ficando a Administração Geral com uma pequena participação 
de apenas $5 \%$.

As oportunidades oferecidas por mercado de trabalho local, nesse sentido, colaboram de modo decisivo para as escolhas e indicam, também, que nem sempre essa decisão acerca da área de preferência está diretamente relacionada às aptidões e habilidades desenvolvidas pelos graduandos durante a graduação (BENDASSOLLI, 2009). Contribuem para a tomada de decisão a atratividade do mercado local e a chegada de organizações com potencial para absorver profissionais especializados nessas áreas, principalmente Marketing, Finanças e de Gestão de Pessoas.

Em relação a vínculo que pretendem seguir após o curso de Administração, conforme resultados, $46 \%$ dos respondentes preferem o setor público, enquanto $24 \%$ preferem o setor privado e $22 \%$ acreditam que o empreendedorismo é uma boa oportunidade para conquistar lucro. Sobre o setor público, isso está associado ao momento atual que tem favorecido a abertura de concursos públicos para o preenchimento das vagas no Brasil, especialmente na região Nordeste, que tem concentrado uma boa parcela das vagas existentes.

Os sujeitos da pesquisa apresentam perspectivas variadas quando questionados sobre salários futuros, quando empossados, vinculados ou contratados, oscilando entre os valores de R $\$ 5.000,00$ (18\%) e $\mathrm{R} \$ 6.000,00$ (10\%), com média salarial de $\mathrm{R} \$ 5.951,85$. Esse perfil demonstra que, dadas as respostas diferenciadas, não existe o conhecimento acertado acerca do valor, em média, dos salários correspondentes que remuneram funções do administrador nos principais segmentos (setor público, privado, acadêmico, empreendedor, etc).

Para Megginson, Mosley e Pietri Jr. (1998), uma carreira administrativa pode ser muito promissora. Os cargos administrativos dão aos profissionais status e o prestígio, são ocupações bastante importantes que fogem das atividades rotineiras. Geralmente, possuem bons salários e os benefícios satisfatórios, além de oferecer uma satisfação social e contato com diversas pessoas.

Por fim, estudantes dos dois últimos anos de Administração da UNIVASF indicaram que, no quesito que revela a satisfação quanto à qualidade do curso ofertado pela instituição de ensino superior, $83 \%$ estão satisfeitos com a grade curricular, os projetos de pesquisa e extensão complementares e os demais serviços vinculados à docência, inclusive professores e estrutura dos espaços. Nesse sentido, os graduandos parecem conscientes sobre o curso de Administração, o mercado local para esses profissionais e a relação existente entre a grade curricular e o foco nas oportunidades apresentadas. A atuação do Administrador, nas áreas das organizações, repercute de maneira decisiva e contribui para a consolidação da imagem. Segundo pesquisa do CFA (2011), a contratação dos Administradores tem sido priorizada pelo mercado, em decorrência da percepção dos empresários sobre os seus conhecimentos, competências, habilidades e atitudes, que diferenciam de outros profissionais. 


\section{Conclusões}

Após a realização da pesquisa e a análise de dados colhidos dos questionários, não há dúvida que a graduação em Administração está realizando papel fundamental na formação e capacitação de profissionais preparados para agregar valor mercado de trabalho, tornando significativas as suas experiências e competências profissionais. O conhecimento, atitudes, habilidades e aptidões pessoais são elementos mais do que essenciais na consolidação da identidade profissional do administrador e orientam a sua conduta e comportamento frente aos desafios e adversidades existentes no ambiente das organizações em que atuam.

Dentro da perspectiva considerada, da problemática de pesquisa e dos objetivos que subsidiaram a construção da análise, cabe, aqui, estabelecer os indicadores para evidenciar a relação entre a atividade profissional dos estudantes dos dois últimos anos do curso de Administração e a sua perspectiva de atuação depois da graduação.

Quanto ao perfil dos sujeitos da pesquisa descoberto a partir dos dados, considerando o $6^{\circ}, 7^{\circ}$, $8^{\circ}$ e $9^{\circ}$ ano, percebeu-se uma grande presença de empregabilidade dos graduandos enquanto estudam e o tempo de vínculo organizacional bastante consolidado e consistente, porém não existe, na maioria dos casos apresentados, salários e benefícios remuneratórios que compensem os esforços e o comprometimento dedicado às atividades, revelando sinais de insatisfação no trabalho e aspirações de mudanças. Está refletido, segundo a necessidade de buscar caminhos e melhores oportunidades de crescimento profissional que remunerem adequadamente o trabalho desenvolvido, no resultado da pesquisa em relação à mudança da atual ocupação após o curso de Administração.

Há a predisposição dos estudantes, composta por muitos jovens, pelas áreas de maior relevância no mercado de trabalho local, no sentido de oferecer uma melhor contribuição ao desenvolvimento e as demandas de que deles exigem. Apesar de um crescimento em outros segmentos, o setor privado ainda é o que mais concentra parcela dos respondentes, ficando, também, o setor público e empreendedor responsáveis por absorver muitos estudantes. No quesito de expectativas de modalidade de trabalho depois do curso, há uma tendência dos estudantes da segunda metade de curso para preparação e realização de concursos públicos e à conquista da estabilidade, além de busca por oportunidades no setor privado, cada vez mais em crescimento na região, e o desejo de abrir e investir em negócios próprios, capazes de trazer ao administrador inúmeras vantagens, inclusive a de aplicação dos conhecimentos na realidade prática do processo de gerenciamento.

O momento vivido pela profissão de Administrador no Brasil não deve estar voltado somente à preparação dos profissionais para as empresas privadas. É necessário defender a formação de um profissional capaz de atuar em diversas formas organizacionais existentes, a exemplo de associações de bairros, cooperativas, microempresas, além das demais formas de organização (CFA, 2011).

A graduação em Administração requer do estudante bem mais do que aptidão inicial, requer a 
visão crítica e sistemática, e, nesse aspecto, a graduação da UNIVASF oportuniza resultados e prepara adequadamente para o mercado de trabalho em expansão. Na pesquisa de 2011, ficou claro que empresas buscam por profissionais que tenham uma visão voltada para o segmento de negócios, que conheçam as áreas da empresa, que tenham a capacidade de exercer liderança e trabalhar o clima motivacional das equipes. Este é um diferencial do administrador de visão ampla das áreas da organização, capaz de liderar, formar e motivar pessoas, enfrentar problemas e buscar soluções, atuar na administração estratégica e ocupar cargos de gerência (WEIBLEN, 2004).

\section{Referências}

BALASSIANO, M.; COSTA, I. Gestão de carreiras: dilemas e perspectivas. Atlas: 1ª Ed., 2006.

BENDASSOLLI, P. Recomposição da relação sujeito-trabalho nos modelos emergentes de carreira. Revista de Administração de Empresas, v. 49, n. 4, p. 387-400, 2009.

BORGES, Cândido et al. Perfil das Recomendações dos Pesquisadores Brasileiros às Políticas Públicas de Empreendedorismo. Administração Pública e Gestão Social, v. 5, n. 1, p. 02-09, 2013.

CARDOSO, Ruth C.L.; SAMPAIO, Helena. Estudantes universitários e o trabalho. RBCS, n0. 26, ano 9, outubro, 2004, p.31.

CONSElHO FERERAL DE ADMINISTRAÇÃO - CFA. Pesquisa Nacional: Perfil, Formação, Atuação e Oportunidades de Trabalho do Administrador. 2011. Disponível em: http://www2.cfa.org.br/administrador/diversos/perfil-do-adminitrador. Acesso em: 20 dez. 2014

COSTA, F. Formação em administração na perspectiva do aluno: valor percebido no curso, percepção do prestígio e identificação com a profissão. In: ENCONTRO DE ENSINO E PESQUISA EM ADMINISTRAÇÃO, 1. Anais... Recife: Anpad, 2007

CRESWELL, John W. Projeto de pesquisa: métodos qualitativo, quantitativo e misto. 3.ed. Porto Alegre: Artmed, 2010.

DIEESE. Pesquisa. Disponível em: www.canalrh.com.br/Mundos/pesquisas. Acesso em: 16 dez 2014

DUTRA, J. S. Administração de carreiras: uma proposta para repensar a administração de pessoas. São Paulo: Atlas, 1998.

DRUCKER, Peter Ferdinand. Introdução à Administração. 3. ed. São Paulo: Thomson Pioneira, 2002.

GOMES, Luiz Flávio. NORONHA, Brena. Educação e a empregabilidade dos jovens: Brasil e Portugal. Disponível em: http://www.lfg.com.br. Acesso em 19 dez 2014.

INSTITUTO BRASILEIRO DE GEOGRAFIA E ESTATÍSTICA - IBGE. Indicadores Sóciodemográficos e de Saúde no Brasil. 2009. Disponível em: http://www.ibge.gov.br/home/estatistica/populacao/indic_socio/2009/. Acesso em: 19 dez. 2014. 
LACOMBE, B.M.B. O aluno de administração de empresas, o trabalho e a construção da carreira profissional: contribuições de um estudo na Grande São Paulo. In: ANAIS: XXVI ENANPAD. Salvador: Anpad, 2002.

MALSCHITZKY, N. Empregabilidade: um modelo para a instituição de ensino superior orientar e encaminhar a carreira profissional dos acadêmicos. Florianópolis: 2004. (Tese de doutorado).

MEGGINSON, Leon C.; MOSLEY, Donald C.; PIETRI JR., Paul H. Administração: Conceitos e Aplicações. 4. ed. São Paulo: Harbra Ltda, 1998.

MELLO, Ana Lúcia Schaefer Ferreira; MOYSÉS, Simone Tetu; MOYSÉS, Samuel Jorge. A universidade promotora de saúde e mudanças na formação profissional. Interface-Comunicação, Saúde, Educação, v. 14, n. 34, p. 683-692, 2010.

PORTUGAL, Juliana. Riscos e vantagens de mudar após os 40. 2012. Disponível em: http://www.gruposoma.net/riscos-vantagens-mudar-profissional. Acesso em 20 dez. 2014

RICHARDSON, Roberto Jarry. Pesquisa Social: métodos e técnicas. 3.ed. São Paulo: Atlas, 2007.

SARSUR, Amyra M.; CRUZ, Marcus Vinicius G.;, BARBOSA, Allan C.Q. Carreira: utopia ou realidade? ANPAD, 2002.

VELOSO, Elza Fátima Rosa et al. Gestão de carreiras e crescimento profissional. Revista Brasileira de Orientação Profissional, v. 12, n. 1, p. 61-72, 2011.

VOESE, Simone Bernardes. Contabilidade por Atividades nos Processos da Gestão Acadêmica nas IES Privadas. Revista Brasileira de Contabilidade. nº 168. nov./dez. 2007.

WEIBLEN, Bruno. O perfil do administrador do século XXI. 2004. Disponível em: http://www.pensandomarketing.com/home/id65.html. Acesso em: 19 dez. 2014.

\section{Como citar este artigo (Formato ABNT):}

CASSUNDÉ, F.R.S.A.; LIMA, A.J.A.; RODRIGUES, C.V.; QUIRINO, C.A.S.; MAIA, L.G. O Que Vou Ser Quando Crescer? A Relação Entre a Atividade Profissional e a Perspectiva de Atuação após o fim do Curso de Graduação. Id on Line Revista de Psicologia, Abril de 2015, vol.9, n.26, Supl. Esp. p. 190-202. ISSN 19811189.

Recebido: $12 / 01 / 2015$

Aceito:09/02/2015 